\title{
Pulmonary lymphangitic carcinomatosis in the course of gastric cancer - Case report
}

\author{
Agnieszka Witczak', Andrzej Prystupa', Małgorzata Olga Zamecka², Andrzej Biłan², \\ Witold Krupski ${ }^{2}$, Jerzy Mosiewicz ${ }^{1}$ \\ ${ }^{1}$ Department of Internal Medicine, Medical University of Lublin, Poland \\ 2 /I Department of Radiology, Medical University of Lublin, Poland
}

Witczak A, Prystupa A, Zamecka MO, Biłan A, Krupski W, Mosiewicz J. Pulmonary lymphangitic carcinomatosis in the course of gastric cancer - Case report. J Pre-Clin Clin Res. 2014; 8(2): 116-119. doi: 10.5604/18982395.1135664

\begin{abstract}
Pulmonary lymphangitic carcinomatosis is a special type of diffuse metastasis of carcinoma in the lymphatic vessels of the lungs. Lymphangitic carcinomatosis is commonly observed in malignancies of the breast, lung, pancreas, colon and cervix as a strong marker for poor prognosis. Presenting with common respiratory symptoms, it may be easily misdiagnosed as other pulmonary interstitial diseases. Pulmonary lymphangitic carcinomatosis is a rare manifestation of metastatic gastric cancer. The presented case describes a patient with pulmonary lymphangitic carcinomatosis in the course of stomach cancer. The primary diagnosis was established based on the exclusion of other interstitial lung diseases, with the use of imaging techniques as well as biochemical, microbiological and cytological findings. The patient's general condition was very severe, rendering him bedridden and therefore not eligible for any treatment, including chemotherapy. He died suddenly before final verification of the diagnosis. Pulmonary lymphangitic carcinomatosis should be suspected in patients with advanced gastric cancer, presenting with symptoms and signs of respiratory disease. Imaging techniques are mostly helpful to establish the diagnosis.
\end{abstract}

\section{Key words}

gastric cancer, pulmonary lymphangitic carcinomatosis, interstitial lung disease

\section{INTRODUCTION}

Gastric cancer is the fourth most common malignant neoplasm and the second leading cause of death from cancer worldwide. Gastric cancer usually carries a poor prognosis since most cases are diagnosed at advanced stages without the possibility of effective treatment $[1,2]$. Surgery is the main treatment strategy for this disease, but chemotherapy trials have provided evidence for the use of perioperative chemotherapy. New molecular agents, mostly monoclonal antibodies, have also been investigated $[3,4]$. Despite some advances in the management of gastric cancer, no significant improvement with regard to overall survival has been achieved and the rates of relapsing of the disease remain high. Patients with unresectable or metastatic gastric adenocarcinoma present the worst prognosis, the more so because their poor general condition due to advanced neoplasm only allows palliative treatment $[2,4]$. As in other adenocarcinomas, pulmonary lymphangitic carcinomatosis (PLC) may develop in the course of gastric cancer. This complication is a special type of diffuse metastasis of carcinoma in the lymphatic vessels of the lungs [5]. Imaging techniques are most helpful for establishing the diagnosis [6]. To date, few reports on PLC in the course of gastric cancer have been published. The presented report concerns the case of pulmonary lymphangitic carcinomatosis in a patient with advanced gastric cancer, who presented symptoms and signs of respiratory disease.

Address for correspondence: Andrzej Prystupa, Chair and Department of Internal Medicine, Medical University, Staszica 16, 20-081 Lublin, Poland

E-mail: aprystup@mp.pl

Received: 16 January 2013; accepted: 18 November 2014

\section{CASE REPORT}

A 47-year-old male patient was admitted to our department due to resting dyspnoea, cough productive of purulent sputum, malaise and central cyanosis. A few months earlier, the patient had been diagnosed with advanced stomach cancer and had been planned for surgery, as well as preoperative chemotherapy. Just before the day planned for admission to the department of surgery the patient started to suffer cough and difficulty in breathing. Respiratory tract infection was diagnosed and the patient received oral antibiotic cefuroxime at the dose of $500 \mathrm{mg}$ twice daily. Since no improvement was achieved the patient was referred to hospital.

On admission, the patient was dyspnoeic, cyanotic, anxious, but alert and responsive. Crackles were present at the base of both lungs. Some wheezing and rhonchi could also be heard. Blood pressure was normal, heart sounds loud and clear, heart rate fast at about 120 per minute, oxygen saturation on air was $88 \%$ and respiratory rate twenty eight breaths per minute. Resting electrocardiography (ECG) and echocardiography showed no significant abnormalities. Chest X-ray revealed bilateral diffused consolidations in the lower lobes of the lungs, including reticulonodular opacities, coarse bronchvascular markings and septal lines, as well as hilar and mediastinal lymphadenopathy. Some pleural effusion was also visible (Fig. 1). Results of haematological and biochemical tests made in the patient are shown in Table 1. Sputum and blood samples were collected for culture. Serologic tests for fungal infections, including evaluation of Candida and Aspergillus antigens, as well as for tuberculosis, were performed with the Quantiferon-tb Gold method. Sputum was also taken for cytological examination and for Mycobacterium tuberculosis direct assessment. 
Table 1. Haematological and biochemical indices in a patient suffering from pulmonary lymphangitic carcinomatosis

\begin{tabular}{|c|c|c|}
\hline Parameter & Value & Reference range \\
\hline Red blood cell count (RBC) $\left(\times 10^{6} / \mathrm{UL}\right)$ & 4.8 & $4.0-5.7$ \\
\hline White blood cell count (WBC) $\left(\times 10^{3} / \mathrm{UL}\right)$ & 12.6 & $4.0-10.0$ \\
\hline Haemoglobin $(\mathrm{Hb}) \mathrm{g} / \mathrm{dl}$ & 13.5 & $13-18$ \\
\hline $\mathrm{Na} \mathrm{mmol} / \mathrm{l}$ & 95.5 & $136-145$ \\
\hline $\mathrm{K} \mathrm{mmol} / \mathrm{l}$ & 2.61 & $3.5-5.1$ \\
\hline $\mathrm{Cl} \mathrm{mmol/l}$ & 55.5 & $98-108$ \\
\hline C-reactive protein (CRP) mg/dl & 134 & $<5$ \\
\hline Procalcitonin $\mathrm{ng} / \mathrm{ml}$ & 0.06 & $<2$ \\
\hline Protein g/dl & 5.87 & $6.4-8.3$ \\
\hline Urea mg/dl & 21.4 & $11-36$ \\
\hline Glucose mg/dl & 97.5 & $60-100$ \\
\hline Creatinine $\mathrm{mg} / \mathrm{dl}$ & 0.5 & $0.6-1.1$ \\
\hline Thyroid-stimulating hormone (TSH) $\mathrm{mlU} / \mathrm{L}$ & 0.356 & $0.27-4.2$ \\
\hline Ca 19-9 antigen $\mathrm{U} / \mathrm{ml}$ & 47.96 & $<40$ \\
\hline Oxygen pressure $\left(\mathrm{pO}_{2}\right)$ on air $\mathrm{mmHg}$ & 61 & $83.0-108.0$ \\
\hline Carbon dioxide pressure $\left(\mathrm{pCO}_{2}\right)$ on air $\mathrm{mmHg}$ & 22 & $35.0-48.0$ \\
\hline $\mathrm{pH}$ on air & 7.48 & $7.35-7.45$ \\
\hline $\mathrm{pO}_{2}$ on oxygen $50 \% \mathrm{mmHg}$ & 76 & $83.0-108.0$ \\
\hline $\mathrm{pCO}_{2}$ on oxygen $50 \% \mathrm{mmHg}$ & 23 & $35.0-48.0$ \\
\hline pH on oxygen $50 \%$ & 7.46 & \\
\hline $\begin{array}{l}\mathrm{N} \text {-terminal of the prohormone brain natriuretic } \\
\text { peptide } \\
\text { (NT-proBNP) pg/ml }\end{array}$ & 196 & $<125$ \\
\hline D-dimer ngFEU/ml & 711.121 & $<500.0$ \\
\hline
\end{tabular}

Since the patient suffered resting dyspnoea with continuous demand for oxygen supply and could not take the supine position, neither high resolution computed tomography (HRCT) of the lungs nor bronchoscopy were possible. Taking into account the most possible causes of diffused interstitial lung infiltrates, the patient received combined antibiotic treatment, including amoxicillin with clavulanic acid at the dose $1,2 \mathrm{~g}$ three times daily i.v., ciprofloxacin $400 \mathrm{mg}$ twice daily i.v. and clarithromycin $500 \mathrm{mg}$ twice

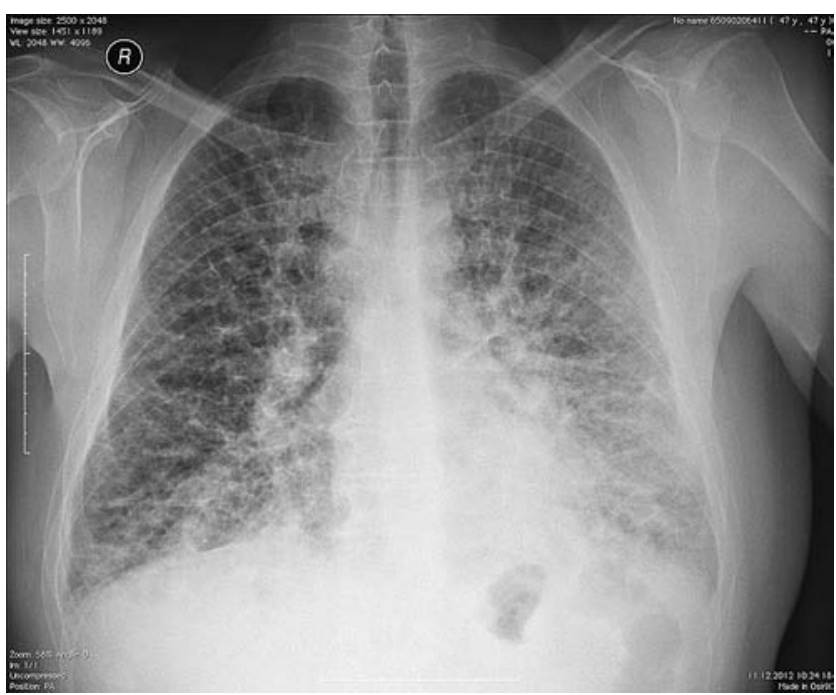

Figure 1. Reticulonodular opacities, coarse bronchvascular markings and septal lines. Hilar and mediastinal lymphadenopathy. Pleural effusion. The radiograph like in the case of interstitial pulmonary oedema

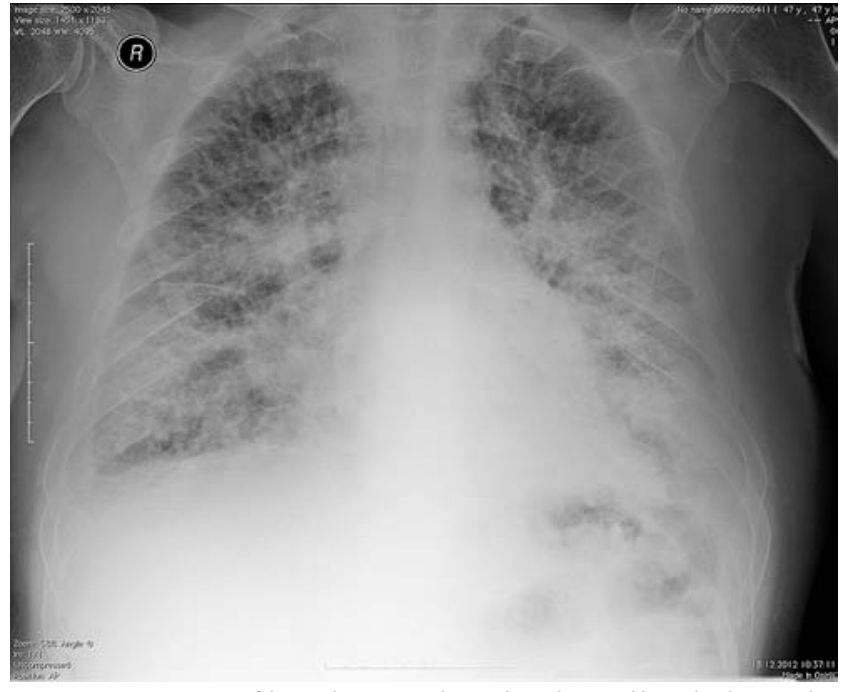

Figure 2. Progression of lung changes. Hilar and mediastinal lymphadenopathy. Pleural effusion

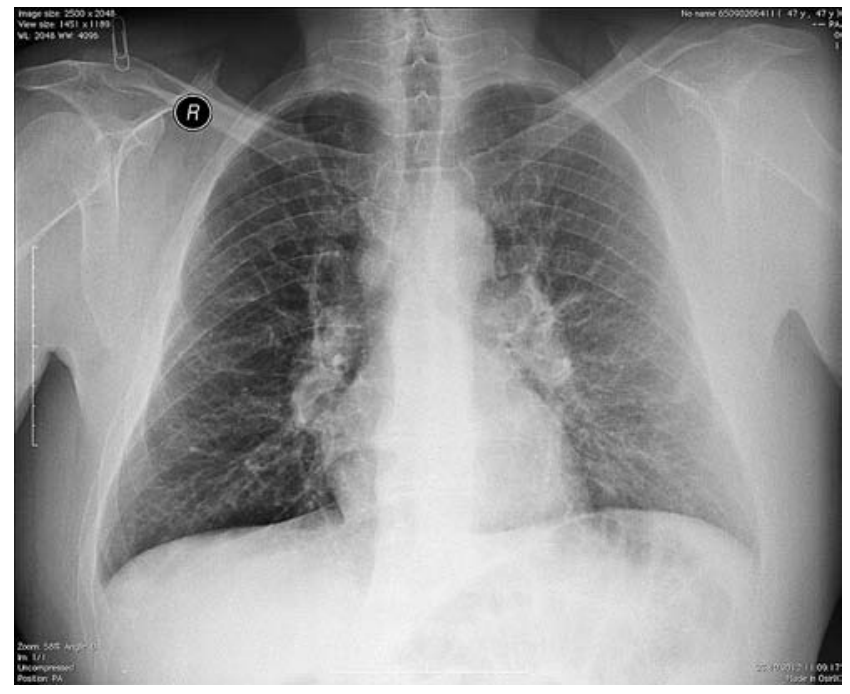

Figure 3. Hilar and mediastinal lymphadenopathy

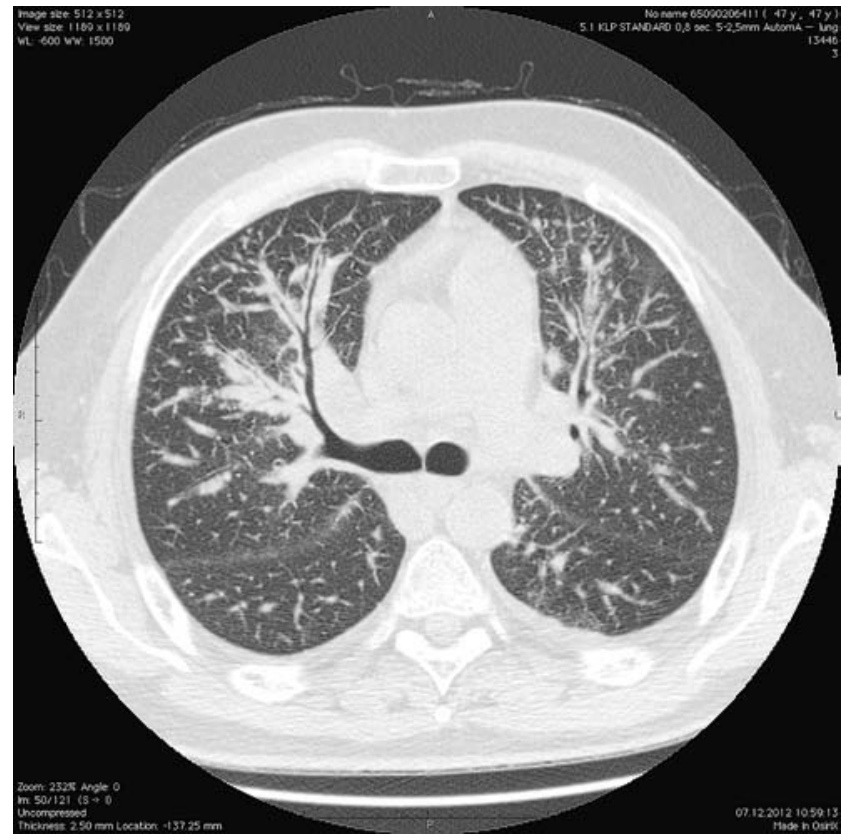

Figure 4. Nodular thickening of interlobular septa and bronchovascular bundles. Septal lines and polygons with nodular appearance. Hilar and mediastinal lymphadenopathy. Pleural effusion 


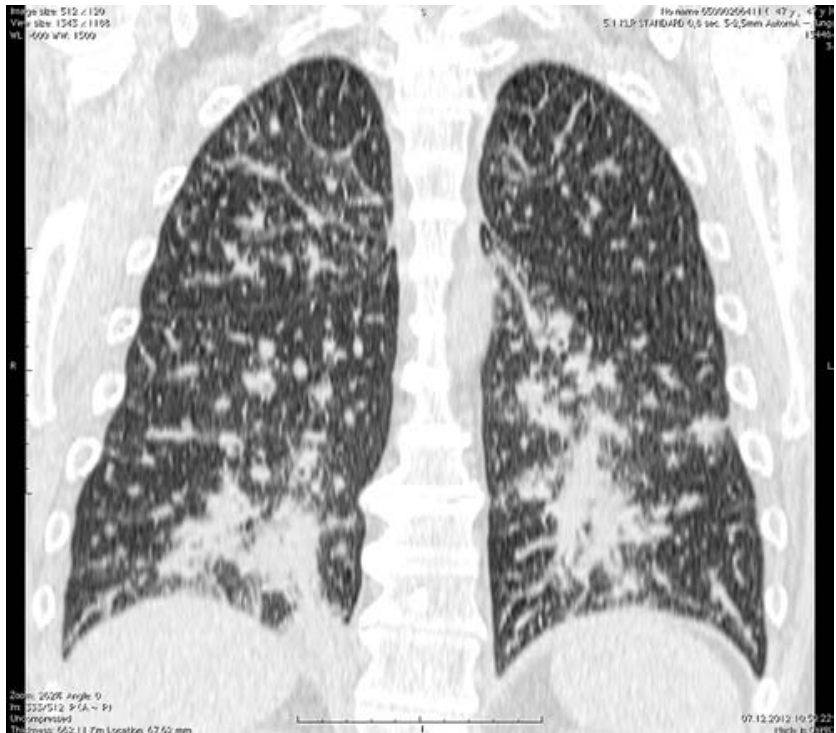

Figure 5. Small centrilobular nodules, thickened centrilobular bronchovascular bundles. Hilar and mediastinal lymphadenopathy. Pleural effusion

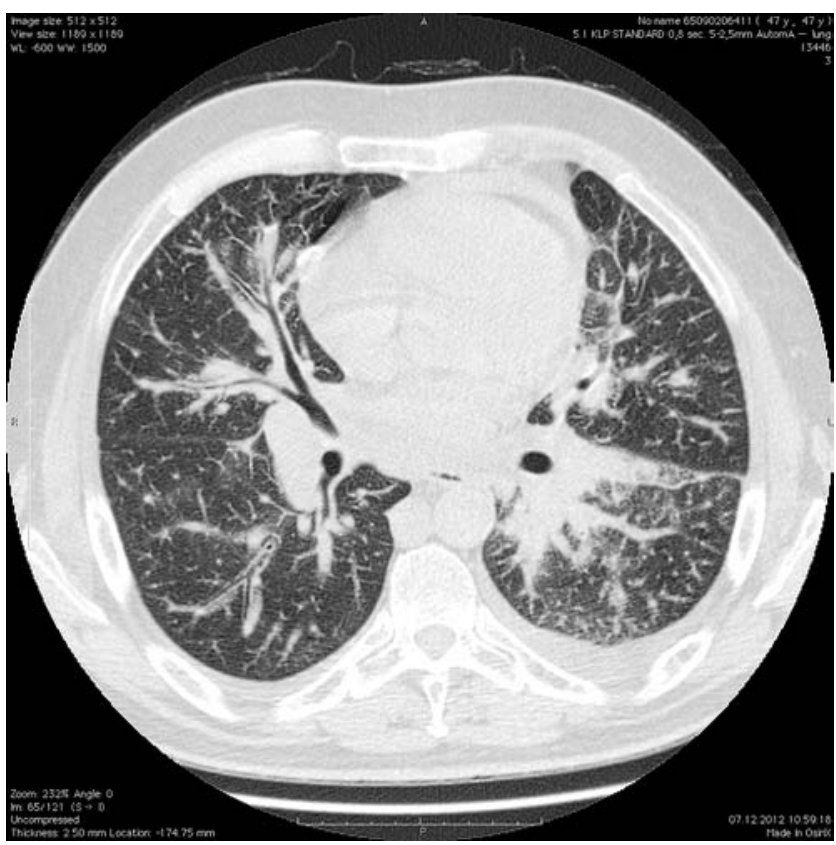

Figure 6. Small centrilobular nodules, thickened centrilobular bronchovascular bundles. Hilar and mediastinal lymphadenopathy. Pleural effusion

daily p.o., and the antifungal drug fluconazole at the dose of $400 \mathrm{mg}$ i.v. Since tuberculosis could have been responsible for the patient's deterioration, rifamazide was added according to the suggestion of the consulting pulmonologist. As a supportive treatment, methylprednisolone $80 \mathrm{mg}$ twice daily, as well as inhaled ipratropium bromide and salbutamol, were given. Theophylline infusion was introduced as the last drug. A preventive dose of $40 \mathrm{mg}$ of enoxaparin was also applied subcutaneously.

Only slight and transient clinical improvement was achieved and X-ray made several days later revealed progression of the primary lung involvement (Fig. 1, 2, 3, $4,5,6)$. X-rays were compared with previous lung imaging, including plain radiograph made two month earlier and HRCT scans made four days before admission to hospital. The only abnormality showing on the X-ray was hilar and mediastinal lymphadenopathy (Fig. 3). HRCT revealed more advanced lung infiltrates, including small centrilobular nodules and thickened centrilobular bronchovascular bundles. Tests for bacterial and fungal infection, as well as Quantiferon-tb Gold results, were either negative or nondiagnostic. Cytological examination of the sputum showed no evident neoplastic cells. Since the course of the disease was fulminant the patient was not eligible for invasive diagnostic procedures and died suddenly after a two-week hospital stay.

\section{DISCUSSION}

Cancers seem to be one of the most common causes of diffuse interstitial lung infiltrates [7]. Lung metastases usually develop by haematogenous spread to the parenchyma, and less frequently via the lymphatic system as PLC, which is diffuse infiltration and obstruction of the parenchymal lymphatic channels by a tumour. Tumour spread through the lymphatic system may be preceded by haematogenous spread to the interstitial space or start directly from the lymph node to the periphery. The tumour obstructs the lymphatic vessels in the peribronchovascular, centrilobular, interlobular and sub-pleural regions and the dilated lymphatic vessels produce interstitial thickening. Unlike interstitial infiltrates, the nodular pattern typical for usual lung metastases results from the spread of the tumour into the lung parenchyma [8]. PLC is one of the rare complications of both thoracic and extra thoracic cancers, including breast, stomach, lung, pancreatic and prostate cancer, all of high propensity for lymphovascular invasion, as well as colorectal, ovarian, skin, renal and cervical tumours. Other neoplasms are rare causes of PLC [9]. In general, it is observed in about $8 \%$ of cases, mostly in adults aged 40-49 [10]. In some cases, PLC may precede or be present at the time of the initial diagnosis of the neoplasm. In the patient in the presented case it was an early complication, but previous lung imaging made soon after the diagnosis of cancer was established showed no lung involvement [11]. Clinical presentation of PLC is not specific, including common respiratory symptoms, such as dyspnoea, dry cough, pleural chest pain, haemoptysis and night sweats. The level of inflammatory markers like C-reactive protein (CRP) may be normal or, as in this patient, elevated. Cancer antigen level is usually elevated [12]. The radiological findings in PLC are pathognomonic. Chest X-ray shows septal lines (Kerley A and B lines), increased bronchovascular markings, linear, reticulonodular and micronodular infiltrates, hilar and mediastinal lymphadenopathy.

HRCT is the imaging technique of choice to confirm the diagnosis of PLC. HRCT findings typical for this disease include thickening of interlobular septa, fissures and bronchovascular bundles, nodularity in pleura and ground glass opacity. They may be seen as limited or diffuse, unilateral or bilateral, symmetric or asymmetric infiltrates. Pleural effusion can also be observed. However, in 30-50\% of cases, chest radiographs show no abnormalities $[13,14]$. Confirmation of PLC may be achieved with transbronchial biopsy, surgical biopsy, bronchoalveolar lavage or sputum cytology. Unfortunately, the fast progression of interstitial infiltrates renders patients intolerant of bronchoscopy; therefore, diagnostic procedures must be limited. Evaluation of tissue samples collected during lung biopsy reveals interstitial oedema and fibrosis, together with neoplastic cells. Unfortunately, in most cases, such information is 
collected only during autopsy. The presence of other distant metastases helps to verify the diagnosis of the malignant neoplasm [15, 16, 17].

The differential diagnosis of diffuse interstitial lung changes should include infections, pulmonary oedema, pulmonary embolism, radiation, drug-induced lung disease, sarcoidosis and miliary tuberculosis. Fever and increased white cell count that may accompany PLC, as observed in the presented case, make it difficult to distinguish it from some infections $[18,19,20]$.

There is no treatment for lung complications, other than that of the primary tumour. Even with modern platinumbased chemotherapy supported with corticoids progression of the infiltrates, is usually fast, which may be observed on serial chest plain radiographs or CT scans. The use of radiation treatment remains controversial since it may promote the spread of the neoplasm $[11,13]$. Long-term survival is very rarely possible with lung involvement. Slow progression or some stability, although not typical, may occur. The average survival with PLC is short and ranges from 11-30 months [8]. The patient in the presented case was not eligible for radical treatment due to severe respiratory compromise which resulted in sudden death.

\section{CONCLUSIONS}

Pulmonary lymphangitic carcinomatosis should be suspected in patients with advanced gastric cancer presenting with symptoms and signs of respiratory disease. Imaging techniques are mostly helpful for establishing the diagnosis. PLC usually denotes poor prognosis, as observed in this case.

\section{REFERENCES}

1.Tsai MM, Wang CS, Tsai CY, Chi HC, Tseng YH, Lin KH. Potential prognostic, diagnostic and therapeutic markers for human gastric cancer. World J Gastroenterol. 2014; 20(38): 13791-13803.

2. Pasechnikov V, Chukov S, Fedorov E, Kikuste I, Leja M. Gastric cancer: Prevention, screening and early diagnosis. World J Gastroenterol. 2014; 20(38): 13842-13862.

3. Shum H, Rajdev L. Multimodality management of resectable gastric cancer: A review. World J Gastrointest Oncol. 2014; 6(10): 393-402.

4. De Vita F, Di Martino N, Fabozzi A, Laterza MM, Ventriglia J, Savastano B, Petrillo A, Gambardella V, Sforza V, Marano L, Auricchio A, Galizia
G, Ciardiello F, Orditura M. Clinical management of advanced gastric cancer: The role of new molecular drugs. World J Gastroenterol. 2014; 20(40): 14537-14558.

5. Zhuang L, Liu X, Hu C, Zhang L, Jiang G, Wu J, Zheng S. Pulmonary lymphangitic carcinomatosis in liver carcinoma: a rare case report and literature review. World J Surg Oncol. 2014; 12: 66.

6. Senthil R, Parghane R, Kashyap R, Bhattacharya A, Mittal BR. F-18 FDG $\mathrm{PET} / \mathrm{CT}$ in Bilateral Diffuse Pulmonary Lymphangitic Carcinomatosis. Nucl Med Mol Imaging. 2012; 46(2): 150-151.

7. Gudatti AK, Marak CP. Pulmonary Lymphangitic Carcinomatosis due to renal cell carcinoma. Case Rep Oncol. 2012; 5(2): 246-252.

8. Bruce DM, Heys SD, Eremin O. Lymphangitis carcinomatosa: a literature review. J R Coll Surg Edinb. 1996; 41(1): 7-13.

9. Liau CT, Jung SM, Lim KE, Shih HN. Pulmonary lymphangitic sarcomatosis from cutaneous angiosarcoma: an unusual presentation of diffuse interstitial lung disease. Jpn J Clin Oncol. 2000; 30(1): 37-39.

10. Wallach JB, McGarry T, Torres J. Lymphangitic metastasis of recurrent renal cell carcinoma to the contralateral lung causing lymphangitic carcinomatosis and respiratory symptoms. Curr Oncol. 2011;18(1): 35-37.

11. Moubax K, Wuyts W, Vandecaveye V, Prenen H. Pulmonary lymphangitic carcinomatosis as a primary manifestation of gastric carcinoma in a young adult: a case report and review of the literature. BMC Res Notes. 2012; 5: 638.

12. Thomas A, Lenox R.Pulmonary lymphangitic carcinomatosis as a primary manifestation of colon cancer in a young adult. CMAJ. 2008;179(4): 338-340.

13. Ikezoe J, Godwin JD, Hunt KJ, Marglin SI. Pulmonary lymphangitic carcinomatosis: chronicity of radiographic findings in long-term survivors. Am J Roentgenol. 1995; 165(1): 49-52.

14. Perez-Lasala G, Cannon DT, Mansel JK, McGehee RP, Allen KG. Case report: lymphangitic carcinomatosis from cervical carcinoma - an unusual presentation of diffuse interstitial lung disease. Am J Med Sci. 1992; 303(3):174-176.

15. Kanthan R, Senger JL, Diudea D. Pulmonary lymphangitic carcinomatosis from squamous cell carcinoma of the cervix.World J Surg Oncol. 2010; 8: 107.

16. Otsubo K, Kubo N, Nakashima N, Izumi M, Nakamori M, Koto H. A juvenile case of pulmonary lymphangitic carcinomatosis caused by sigmoid colon cancer with a component of micropapillary carcinoma. Intern Med. 2011; 50(20): 2361-2365.

17. Gilchrist FJ, Alton H, Brundler MA, Edwards L, Plunkett A, Rao S. Pulmonary lymphangitic carcinomatosis presenting as severe interstitial lung disease in a 15-year-old female. Eur Respir Rev. 2011; 20(121): $208-210$.

18. Erbes R, Oettel K, Raffenberg M, Mauch H, Schmidt-Ioanas M, Lode $\mathrm{H}$. Characteristics and outcome of patients with active pulmonary tuberculosis requiring intensive care. Eur Respir J. 2006; 27(6): 12231228.

19. Elicker B, Pereira CA, Webb R, Leslie KO. High-resolution computed tomography patterns of diffuse interstitial lung disease with clinical and pathological correlation. J Bras Pneumol. 2008; 34(9): 715-744.

20. Lu SJ, Loo SW. Images in emergency medicine. Fever, cough and weight loss. Miliary tuberculosis. Ann Emerg Med._2012; 60(4): 9-10. 